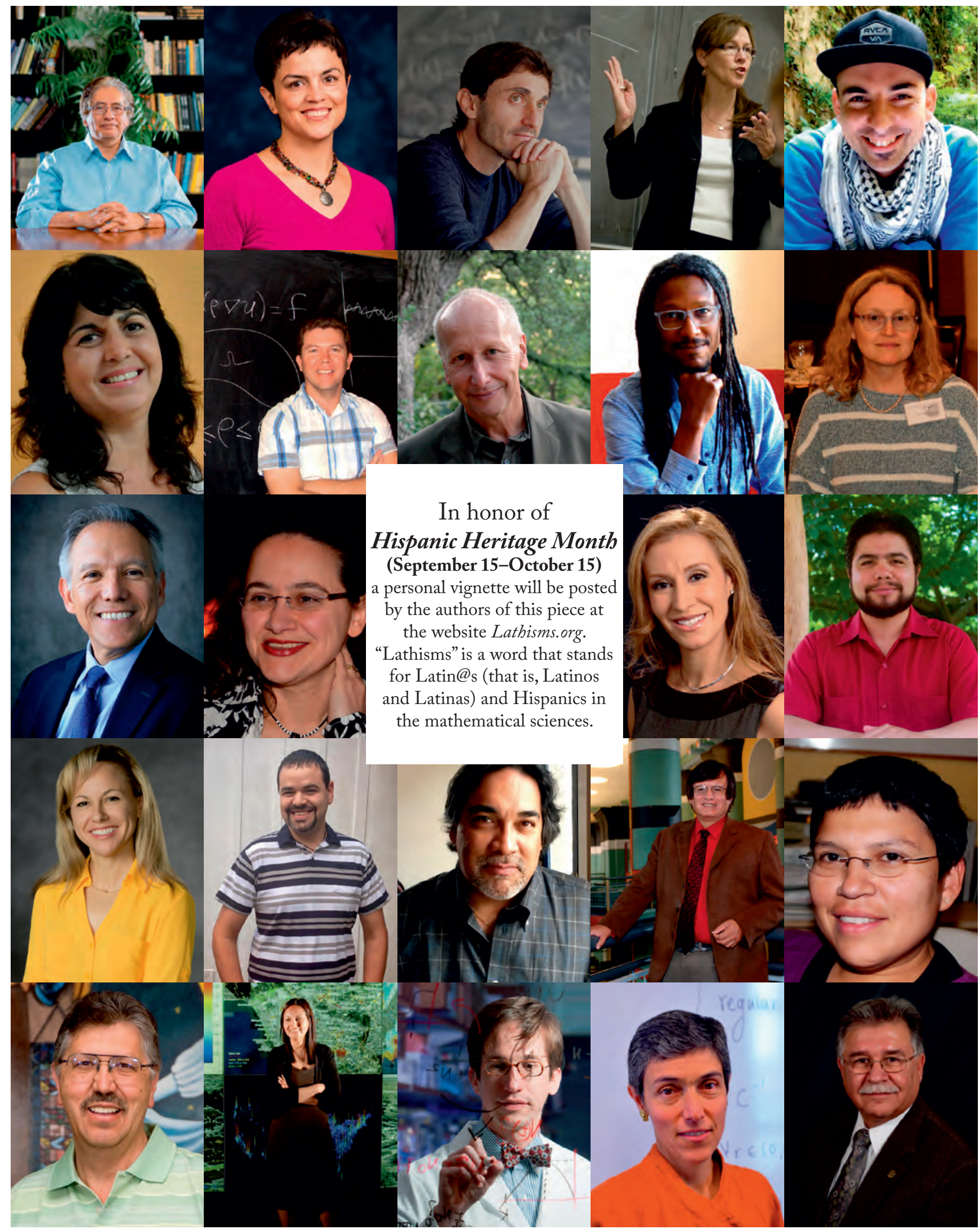


Carlos Castillo-Chavez

Brisa Sánchez

Marcelo Aguiar

Minerva Cordero

Federico Ardila-Mantilla

Ivelisse Rubio

Johnny Guzmán

Luis Caffarelli

José G. Mijares

Marianne Korten

Juan Meza

Mariel Vazquez

Erika Camacho

Luis Garcia-Puentes

Montserrat Fuentes

Edgar Dueñez

Ricardo Cortez

Richard Tapia

Rosa Orellana

Rodrigo Bañuelos

Sara del Valle

Santiago Schnell

Tatiana Toro

William Vélez
Photo provided by Simon A. Levin MCMSC at ASU.

Photo courtesy of U-M SPH Office of Marketing and Communications.

Photo (c) Cornell University.

Photo courtesy of The University of Texas at Arlington.

Photo by May-Li Khoe.

Photo by Bianca Colón.

Photo courtesy of Johnny Guzmán.

Photo (c) The Institute for Computational Engineering and Sciences,

The University of Texas at Austin.

Photo courtesy of Adriana Rondon-Rivero.

Photo by Kristen Schweitzer.

Photo courtesy of UC Merced.

Photo courtesy of Lynn Zechiedrich, PhD.

Photo courtesy of Erika Camacho.

Photo taken by Lisa Waters for the Pacific Undergraduate

Research Experience in Mathematics Program.

Photo (c) VCU.

Photo by Suzanne Sadedin, used with permission.

Photo courtesy of Kathleen Kozar.

Photo courtesy of Tommy LaVergne, Rice University.

Photo courtesy of Gael Popescu.

Photo courtesy of Rodrigo Bañuelos.

Photo courtesy of LeRoy N. Sanchez, Los Alamos National Laboratory.

Photo courtesy of Santiago Schnell, University of Michigan, Medical School.

Photo courtesy of Dan Pollack.

Photo courtesy of William Vélez. 


\title{
Lathisms: Latin@s and Hispanics in Mathematical Sciences
}

\author{
Alexander Diaz-Lopez, Pamela E. Harris, \\ Alicia Prieto Langarica, Gabriel Sosa
}

$\mathrm{N}$ ational Medal of Science recipient Richard Tapia often uses the phrase "Excellence comes in all flavors" to assert that neither race nor any other characterization determines talent or success. This statement is particularly true in our field of mathematics. Despite this, there is still a major underrepresentation of Latin@s (Latinas and Latinos) and Hispanics in the mathematical sciences. Although 17 percent of the US population is Hispanic, ${ }^{1}$ only 3.5 percent of $2014 \mathrm{PhDs}$ in mathematics were Hispanic. ${ }^{2}$

One important step that the mathematical community can take to address this underrepresentation issue is to provide visibility to the research and mentoring contributions of Latin@s and Hispanics, as it is well known that women and minorities greatly benefit from having role models from their own demographics and backgrounds. To this end, we will showcase one Latin@/Hispanic mathematician per day through the AMS Twitter account (@amermathsoc) and the website Lathisms . org during the period of September 15 to October 15. This coincides with the United States observance of Hispanic Heritage Month, a time to acknowledge the contributions that Latin@s and Hispanics have made in the US and to celebrate our culture and heritage.

Six samples are presented in this article.
Alexander Diaz-Lopez is visiting assistant professor at Swarthmore College. His email address is adiazlo1@swarthmore. edu.

Pamela E. Harris is assistant professor at Williams College. Her email address is pame1a.e.harris@wi 11iams.edu.

Alicia Prieto-Langarica is associate professor at Youngstown State University. Her email address is apri etolangarica@ysu. edu.

Gabriel Sosa is visiting assistant professor at Amherst College. His email address is gsosa@amherst. edu.

1 www. census.gov/newsroom/facts-for-features/2015/ cb15-ff18.htm1

${ }^{2}$ Supplemental Table D.5: Gender, Race/Ethnicity \& Citizenship of 2013-2014 New Doctoral Recipients, July 1, 2013-June 30, 2014, www. ams.org/profession/data/annua1-survey/2013SurveyNewDoctorates-Supp-Tab1eD2.pdf.

\section{Photo Credits}

Photo of Mariel Vazquez courtesy of Lynn Zechiendrich, PhD.

Photo of Ricardo Cortez courtesy of Kathleen Kozar. Photo of Tatiana Toro courtesy of Dan Pollack. Photo of Juan Meza courtesy of UC Merced. Photo of Rosa Orellana courtesy of Gael Popescu. Photo of Santiago Schnell courtesy of Santiago Schnell/ University of Michigan, Medical School.

For permission to reprint this article, please contact: reprint-permission@ams .org. DOI: http://dx.doi.org/10.1090/noti1425 


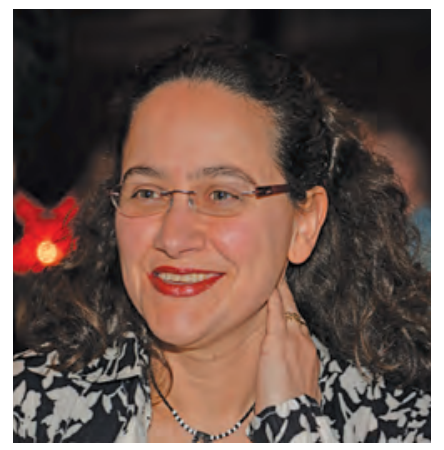

Mariel Vazquez, professor of mathematics and of microbiology and molecular genetics at UC Davis.
The Census Bureau announced last year that Hispanics are the largest ethnic group in California, but only 2 percent of Latinos aged eighteen to twenty-four were enrolled at the University of California. I feel a strong sense of responsibility to serve as a role model and mentor to Hispanics, Latin@s, and other underrepresented minorities in STEM to help close this gap. Hispanic Heritage Month offers a wonderful opportunity to highlight the work of people whose faces are not often seen in our community, thus encouraging students of color to pursue a degree in mathematics and other STEM-related fields.

-Mariel Vazquez

\section{Bio and Research}

Mariel Vazquez is professor of mathematics and of microbiology and molecular genetics at UC Davis. She works at the interface of mathematics and biology. Her research uses tools from pure mathematics (knot theory, low-dimensional topology, graph theory) to study important biological questions, especially the packing and function of DNA. For example, she has studied the topological changes (changes in shape), of DNA affected by enzymes, how chromosomes are changed by radiation and cancer, and how DNA is packed up within a cell. Her work, often collaborative, has provided keen insights into the packing of DNA and into the mechanism of enzymes involved in important biological processes such as DNA replication and DNA repair.

\section{Awards and Service}

Mariel is the recipient of numerous awards, including the 2016 Blackwell-Tapia Prize, the 2015 Dorothy Wrinch Endowed Lectureship at Smith College, a 2014 CAMPOS scholarship at UC Davis, the 2014 Mohammed Dahleh Distinguished Lectureship at UC Santa Barbara, a 2012 US Presidential Early Career Award for Scientists and Engineers (PECASE), and a 2011 NSF CAREER Award. The PECASE honored her for excellent interdisciplinary and international research at the interface of mathematics and biology and for creativity and dedication to recruiting, training, mentoring, and helping students from underrepresented groups achieve their goals.

Mariel serves on the Human Resources Advisory Committee of the Mathematical Sciences Research Institute (MSRI). She has served on the Advisory Board at the National Institute of Mathematical and Biological Synthesis (NIMBioS). She has been actively involved with SACNAS as co-organizer of Scientific Symposia as speaker and mentor, and she has also helped secure federal funding to support mathematics participation. She has been involved as organizer and keynote speaker at the Modern Math Workshop, sponsored by the NSF mathematics institutes.

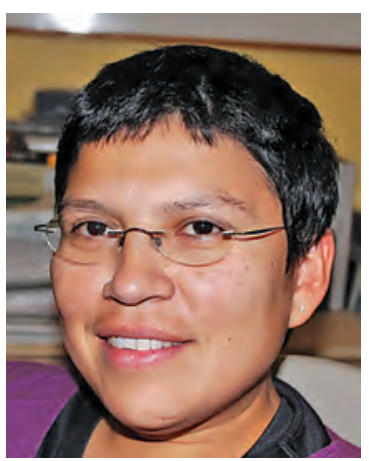

Rosa Orellana, professor of mathematics at Dartmouth College.

\section{ROSA ORELLANA}

\section{Bio and Research}

Rosa Orellana is professor of mathematics at Dartmouth College. She works in the area of algebraic combinatorics, an area of mathematics that studies objects that have combinatorial and algebraic properties with the goal of using algebraic methods to answer combinatorial questions and, conversely, applying combinatorial techniques to problems in algebra. Recently her work has focused on the Kronecker product of two irreducible representations of the symmetric group. She and Mike Zabrocki, in joint work, introduced two new bases for the ring of the symmetric group that they hope will lead to progress on the Kronecker product.

\section{Awards and Service}

Early in her career Rosa received a University of California President's Postdoctoral Fellowship at UC San Diego. Since then she has mentored many students on research projects, and during the summer in 2013 she led a group of eighteen minority students for MSRI-UP. She received the John M. Manley Huntington Memorial Award at Dartmouth for outstanding research, teaching, and mentoring. She has also served as the advisor for the Dartmouth math club, co-funded a chapter of the Association for Women in Mathematics in an effort to increase the number of women taking and majoring in mathematics at Dartmouth, and has organized Sonia Kovalevsky Math Days to encourage middle and high school girls in the community to study mathematics. 


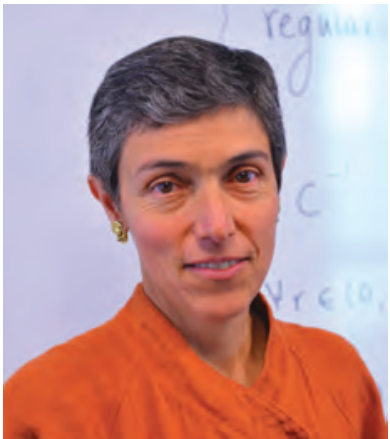

Tatiana Toro, Robert R. \& Elaine F. Phelps Professor in Mathematics at the University of Washington.

\section{Bio and Research}

Tatiana Toro is Robert R. \& Elaine F. Phelps Professor in Mathematics at the University of Washington. She is working at the interface of geometric measure theory, harmonic analysis, and partial differential equations. The interaction between these three areas has been one of the pillars of her research. Her work focuses on understanding mathematical questions that arise in an environment where the known data is very rough. In particular, she studies the properties of interfaces arising in "noisy" minimization problems. The main premise of her work is that under the right lens, objects which at first glance might appear to be very irregular do exhibit quantifiable regular characteristics. With C. Kenig she introduced the notion of chord arc domains, setting a new framework to study boundary regularity questions for second-order partial differential operators. They laid the foundation of what has become a new, rapidly developing area within PDEs. Her work with C. Kenig and D. Preiss brought tools from geometric measure theory to study basic questions about the structure of harmonic measure. Their ideas have provided a new and original approach to understanding the relationship between the geometry of a domain and the regularity at the boundary of the solutions to second-order partial differential equations. Currently she is very excited about a program she has been developing with G. David and M. Engelstein concerning the properties of almost minimizers. The goal is to show that even in the presence of "noise" variational characteristics preserve regularity up to first order.

\section{Awards and Service}

Her awards include a Guggenheim Foundation Fellowship, a Simons Foundation Fellowship, an Alfred P. Sloan Research Fellowship, and a National Science Foundation Mathematical Sciences Postdoctoral Research Fellowship. She was an invited speaker at ICM 2010 in Hyderabad, India. She delivered an invited address at the Joint Mathematics Meeting in New Orleans, Louisiana, in January 2011 and the NAM Clayton-Woodard Lecture at the Joint Mathematics Meetings in Seattle, Washington, in January 2016.

Tatiana has served in numerous leadership positions (including director) at the Pacific Institute for the Mathematical Sciences and is a current member of the Board of Trustees of the Institute for Pure and Applied Mathematics (IPAM). Recently she has been involved in efforts to promote diversity in the mathematical sciences. In the spring of 2015 she co-organized the first Latinos in the Mathematical Sciences (Lat@math) conference at IPAM. The second edition of this conference is being planned for 2018 .

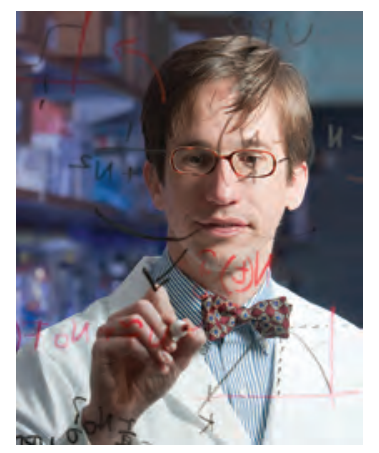

Santiago Schnell, professor in the Department of Molecular \& Integrative Physiology and Department of Computational Medicine \& Bioinformatics at the University of Michigan Medical School. He is also a William K. Brehm Investigator at the Brehm Center for Diabetes Research. rent Opinion in Systems Biology, and Cancer Research. He is a member of the Educational League of Excellence at the University of Michigan Medical School and received the University of Michigan Endowment for Basic Science Teaching Award. He is a recipient of the 21st Century Scientist Award from the James S. McDonnell Foundation and is an elected Fellow of the Royal Society of Chemistry. Presently, he serves as the president for the Society of Mathematical Biology. 


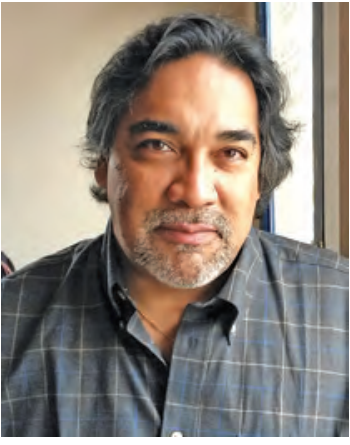

Ricardo Cortez, Pendergraft William Larkin Duren Professor in Mathematics at Tulane University and director of the Center for Computational Science.

\section{Bio and Research}

Ricardo Cortez is Pendergraft William Larkin Duren Professor in Mathematics at Tulane University and director of the Center for Computational Science. He is internationally regarded as a leading researcher in fluid dynamics and mathematical modeling. His research interests are in developing and analyzing computational methods for the simulation of biological fluid flows. His elegant and easily implemented method of regularized stokeslets has become a standard computational framework for engineers and physicists studying fluid flow around microorganisms. Throughout his career, Ricardo has promoted interdisciplinary collaborations and continues to integrate computational investigations in joint research activities with experimentalists and applied scientists. Additional research interests include mathematical modeling and secondary mathematics education.

\section{Awards and Service}

Early in his career Ricardo received a Career Enhancement Fellowship for Junior Faculty from Underrepresented Groups from the Woodrow Wilson National Fellowship Foundation. For his mentoring work, he has been honored with the SACNAS Distinguished Undergraduate Institution Mentor Award and the SACNAS Presidential Service Award. He was the 2012 recipient of the Blackwell-Tapia Prize for significant contributions to research and for serving as a role model for mathematical scientists and students from underrepresented minority groups.

Ricardo has been a member of numerous committees for such organizations as the National Science Foundation (NSF), Mathematical Sciences Research Institute (MSRI), Mathematical Biosciences Institute, Mathematical Association of America (MAA), Society for Advancement of Chicanos/Hispanics and Native Americans in Science (SACNAS), and Society for Industrial and Applied Mathematics (SIAM), among many others. In addition he served as a founding director of the summer research program MSRI-UP from 2007 to 2014.

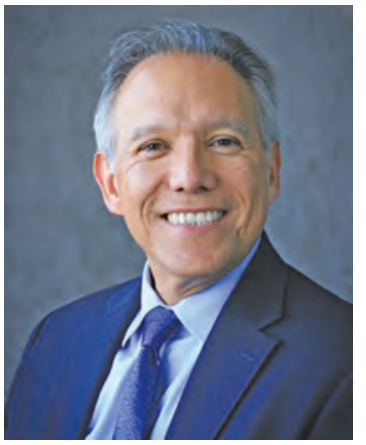

Juan Meza, dean of the School of Natural Sciences and Professor of applied mathematics at the University of California, Merced.

\section{JUAN MEZA}

\section{Bio and Research}

Juan Meza is dean of the School of Natural Sciences at the University of California, Merced. His current research interests include nonlinear optimization with an emphasis on methods for parallel computing. He has also worked on various scientific and engineering applications, including scalable methods for nanoscience, power grid reliability, molecular conformation problems, optimal design of chemical vapor deposition furnaces, and semiconductor device modeling. Prior to joining UC Merced, Dr. Meza served as department head and senior scientist for High Performance Computing Research at E. O. Lawrence Berkeley National Laboratory, where he led research programs in computational science and mathematics, computer science and future technologies, scientific data management, visualization, and numerical algorithms and application development.

\section{Awards and Service}

Juan received the 2013 Rice University Outstanding Engineering Alumni Award and was named to Hispanic Business Magazine's Top 100 Influentials in the area of science. In addition, he has been elected a Fellow of the AAAS and was the 2008 recipient of the Blackwell-Tapia Prize and the SACNAS Distinguished Scientist Award. He was also a member of the team that won the 2008 ACM Gordon Bell Award for Algorithm Innovation.

Juan has served on numerous external committees including the National Research Council Board on Mathematical Sciences and Their Applications, DOE's Advanced Scientific Computing Advisory Committee, the Human Resources Advisory Committee for the Mathematical Sciences Research Institute, the boards of trustees for IPAM and SIAM, the Board of Governors for the Institute for Mathematics and its Applications, and the External Advisory Committee for the National Partnership for Advanced Computational Infrastructure. 